Article

\title{
Cordyceps militaris Grown on Germinated Soybean Suppresses KRAS-Driven Colorectal Cancer by Inhibiting the RAS/ERK Pathway
}

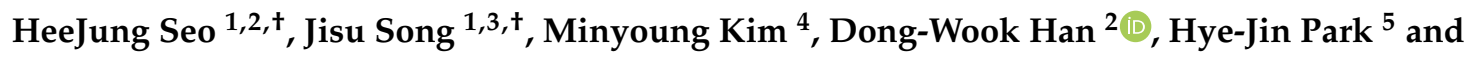 \\ Minjung Song ${ }^{1, *(\mathbb{D})}$ \\ 1 Department of Food Biotechnology, Division of Bioindustry, Silla University, Busan 46958, Korea; \\ ssk4623@naver.com (H.S.); jisu632@naver.com (J.S.) \\ 2 Department of Cogno-Mechatronics Engineeering, College of Nanoscience \& Nanotechnology, \\ Pusan National University, Busan 46241, Korea; nanohan@pusan.ac.kr \\ 3 Department of Medical Science, School of Medicine, Pusan National University, Yangsan 50612, Korea \\ 4 Department of Electronics \& IT Media Engineering, Seoul National University of Science \& Technology, \\ Seoul 01811, Korea; mkim21@gmail.com \\ 5 Department of Food Biotechnology, Gachon University, Kyungji-do 13120, Korea; nimpi79@daum.net \\ * Correspondence: songmj@gmail.com; Tel.: +82-51-999-5358; Fax: +82-51-999-5458 \\ + These authors contributed equally to this work.
}

Received: 10 December 2018; Accepted: 19 December 2018; Published: 21 December 2018

\begin{abstract}
Cordyceps militaris is a commonly used medicinal mushroom containing various therapeutic effects such as anti-inflammatory, anti-allergic, and anti-cancer activities. This study examined whether Cordyceps militaris on germinated soybeans (GSC) has a suppressive effect on a v-ki-ras2 Kirsten rat sarcoma viral oncogene homolog (KRAS)-driven colorectal cancer which is notorious for its un-druggable features and the ineffectiveness of conventional therapies against it. GSC extract was prepared and its proximate composition and amino acids were analyzed. The suppressive effects were investigated with the KRAS-driven colorectal cancer cell-line, SW480. SW480 proliferation, clonogenic potential, apoptosis, and the RAS/extracellular signal-regulated kinase (ERK) pathway under the GSC treatment were analyzed by 3-(4,5-dimethylthiazol-2-yl)-5-(3-carboxymethoxyphenyl)-2-(4-sulfophenyl)-2H-tetrazolium (MTS) assay, flow cytometry, and Western blot, respectively. An in vivo experiment with the SW480 xenograft mouse model was performed. As a result, GSC suppressed cell proliferation by inducing the apoptosis of KRAS-driven colorectal cancer cells and inhibited clonogenic capabilities. The decrease of KRAS and ERK phosphorylation was detected by Western blot. Tumor growth was significantly suppressed when GSC was introduced to the tumor-xenograft mouse model. In conclusion, GSC suppressed KRAS-driven colorectal cancer growth both in vitro and in vivo, and can be used as an alternative or simultaneous approach in colorectal cancer therapy.
\end{abstract}

Keywords: Cordyceps militaris; colorectal cancer; SW480; KRAS

\section{Introduction}

Colorectal cancer (CRC) is the third most prevalent cancer worldwide [1]. Approximately 1.7 million new cases were diagnosed in 2016 and 830,000 people were estimated to have died as a result [1]. In general, the incidence of CRC is high in developed countries compared to developing countries, but the cases are increasing worldwide due to nutritional transitions. The increasing prevalence has prompted extensive research into the development of therapies. On the other hand, $30 \%$ to $40 \%$ of CRC patients have a v-ki-ras2 Kirsten rat sarcoma viral oncogene homolog (KRAS)-driven CRC, which is difficult to target with drugs due to its notorious 'un-druggable' property 
and ineffective response to conventional therapies [2]. RAS proteins are the most powerful cancer drivers. KRAS-driven colorectal cancer is initiated from the epidermal growth factor (EGF) binding to the EGF receptor (EGFR), which activates GTP-bound KRAS. The activated KRAS continuously transmits a signal to the downstream RAS-ERK cell regulation pathways. The ERK proteins activated by their phosphorylation are translocated to the nucleus and activate the transcription factors that involve the cell cycle progression and transcription. Hence, they are involved directly in tumor progression. The abnormal levels of phosphorylated mitogen-activated protein kinases (MAPKs), ERK1, and ERK2 are observed in $\sim 30 \%$ of human tumors [2,3]. To inhibit RAS activation, targeting EGFR with monoclonal antibodies such as Cetuximab has emerged as a potential therapeutic $[4,5]$. However, monoclonal antibody therapeutics have side effects and a second resistance harboring KRAS mutation, which accounts for $30 \%$ to $40 \%$ of CRC patients [6-9].

There is evidence that natural products exhibit anti-colorectal cancer activities. For example, Frondoside A isolated from a sea cucumber enhanced the anti-cancer effects of colon cancer drugs [10]. Imperatorin isolated from Angelica dahurica suppressed the proliferation and angiogenesis of colorectal cancer by targeting hypoxia-inducible factor (HIF)- $1 \alpha$ [11]. Han et al. reported that Ginsenoside 20 -Rh2 from Panax ginseng inhibited colon cancer cell proliferation through the JAK2/STAT3 pathway [12]. However, there are few natural products reported to act against KRAS-driven colorectal cancer.

Cordyceps militaris is a functional mushroom that has been used traditionally to treat inflammatory diseases [13] and improve the immune system [14,15]. Several reports have demonstrated its suppressive activity on cancer progression $[16,17]$. On the other hand, naturally occurring Cordyceps militaris has limited availability because of its high production cost. Park et al. inoculated Cordyceps militaris onto germinated soybeans (Glycine max (L.) Merr) (GSC) to improve its productivity and studied its functions [18-20]. In their functional study, GSC exhibited therapeutic activity on colon inflammatory disease [18], allergic diseases [19,20], and cancer [21]. Considering the information above, the extracts of GSC containing chemical compounds may modulate the proliferation and progression of mCRC.

This study examined the anti-cancer activity of GSC on G12V (mutation occurring at codon 12)-KRAS driven colorectal cancer. The amino acid composition was analyzed. The proliferation profile and clonogenic features of the KRAS-driven cell line, SW480, were evaluated under the GSC treatment. The RAS/MEK/ERK and AKT/PI3K pathways on cancer cell death were investigated. In addition, GSC extracts were administered to colon cancer cell xenograft mice to examine its anti-cancer effects in vivo.

\section{Materials and Methods}

\subsection{Preparation of Cordyceps militaris Grown on Germinated Soybeans Extract}

The Cordyceps militaris (Kucari 0906) grown on germinated soybeans (GSC) was provided by the Cell Activation Research Institute (CARI, Seoul, Korea). Authenticated voucher specimens of GSC were deposited in the Herbarium at the Department of Food Science and Biotechnology, Gachon University (Seongnam, Gyeonggido, Korea). GSC was ground to a fine powder with a grinder and reconstituted with $80 \%$ ethanol for $48 \mathrm{~h}$. The solution was dried with a rotary evaporator under vacuum and stored at $-20{ }^{\circ} \mathrm{C}$ until needed. GSC was then dissolved in distilled water.

\subsection{Proximate Composition and Analysis of Amino Acids}

The GSC sample was analyzed for its crude protein, crude fat, and crude ash contents. The crude protein content was determined based on the total nitrogen content and the Kjeldahl method. The crude fat was extracted with petroleum ether by the Soxhlet method (AOAC, 2000) [22]. The contents of all the amino acids were determined by using an amino acid analyzer (Biochrom $30^{+}$, Biochrom, Cambridge, UK). 


\subsection{Cell Viability by the MTS Proliferation Assay and DAPI/PI Staining}

The G12V KRAS-mutated SW480, G12D KRAS-mutated LS513, G13D KRAS-mutated HCT116, KRAS-WT/v-raf murine sarcoma viral oncogene homolog B1 (BRAF)-mutated HT-29, KRAS-WT/BRAF-WT Caco-2 CRCs and KRAS-WT/BRAF-WT A549 lung cancer cells were purchased from the American Type Culture Collection (Rockville, MD, USA). Cells were maintained in RPMI-1640 or DMEM (Invitrogen, Carlsbad, CA, USA) with 10\% fetal bovine serum (FBS, Invitrogen) and 100 $\mathrm{U} / \mathrm{mL}$ penicillin-streptomycin (Sigma, St. Louis, MO, USA). The media was changed every 2 to 3 days with regular passage 1 to 2 times a week. Before cell seeding, cells were detached from the flasks with $0.25 \%(v / v)$ trypsins and $0.02 \%$ Ethylene diamine tetraacetic acid (EDTA) solution. For the cell viability assay, the cells were seeded onto $96-$ well plates $(20,000$ cells/well) and treated with an increasing concentration of GSC $(1-500 \mu \mathrm{g} / \mathrm{mL})$ after $24 \mathrm{~h}$. For proliferation analysis, 3-(4,5-dimethylthiazol-2-yl)-5-(3-carboxymethoxyphenyl)-2-(4-sulfophenyl)-2H-tetrazolium (MTS) kit (Promega, Fitchburg, WA, USA) was used, according to the manufacturer's instructions. More specifically, the MTS reagent was added on the media for 1 hour at $37^{\circ} \mathrm{C}$ and absorbance readings were taken at 490 nm (Model 550, Bio-Rad, Hercules, CA, USA).

For 4',6-diamidino-2-phenylindole (DAPI) / propidium iodide (PI) staining, the cells were fixed with $4 \%$ paraformaldehyde (Sigma). The cells were stained with $1 \mu \mathrm{g} / \mathrm{mL}$ of $4^{\prime}, 6$-diamidino-2-phenylindole (DAPI, Sigma) for $10 \mathrm{~min}$ at room temperature, which was followed by propidium iodide (Sigma) incubation in the dark. The stained cells were then observed under an inverted fluorescence microscope $\left(\right.$ EVOS $^{\circledR}$, Thermo Fisher Scientific, Waltham, MA, USA).

\subsection{Clonogenic Assay}

For a clonogenic assay, the cells were seeded onto a 6-well plate (1000 cells/well) [23]. After one day, the cells were treated with GSC extracts in different concentrations $(1,10,100$, and $500 \mu \mathrm{g} / \mathrm{mL})$ and Cetuximab $(30 \mu \mathrm{g} / \mathrm{mL})$. After the 10 -day cultivation, the cells were stained with a $0.05 \%$ crystal violet (Sigma) for $20 \mathrm{~min}$ at room temperature. The experiments were performed in triplicate.

\subsection{Flow Cytometry}

The extent of SW480 apoptosis after GSC treatment was evaluated by using an Annexin V-fluorescein isothiocyanate (FITC)/PI apoptosis detection kit (BD Biosciences, San Jose, CA, USA), according to the manufacturer's instructions. SW480 colorectal cancer cells were seeded overnight in a 6-well plate $\left(5 \times 10^{5}\right.$ cells/well $)$ and treated with Cetuximab $(30 \mu \mathrm{g} / \mathrm{mL})$ and the GSC extract $(1-500 \mu \mathrm{g} / \mathrm{mL})$. After $24 \mathrm{~h}$, the cells were harvested, washed in ice-cold PBS, and collected by centrifugation at $500 \mathrm{~g}$ for $10 \mathrm{~min}$. The cells were stained simultaneously with FITC-labeled annexin $\mathrm{V}$ $(5 \mu \mathrm{L})$ and PI $(5 \mu \mathrm{L})$ at room temperature for $10 \mathrm{~min}$ and protected from light. The stained cells were analyzed by using a fluorescence-activated cell sorter flow cytometer (FC 500 Series Flow Cytometry, Beckman Coulter, Indianapolis, IN, USA). At least 10,000 cells were used for each analysis and the experiments were conducted in triplicate.

\subsection{Western Blotting}

The cells were seeded in 6-well plates with a density of $\left(5 \times 10^{5}\right.$ cells/well $)$ and treated with GSC $(1-500 \mu \mathrm{g} / \mathrm{mL})$ for $48 \mathrm{~h}$. The cells were detached, washed in cold PBS, and re-suspended in RIPA buffer containing the protease inhibitors (Sigma). The suspension was kept on ice for $20 \mathrm{~min}$ and then centrifuged at $15,000 \times g$ for $30 \mathrm{~min}$ at $4{ }^{\circ} \mathrm{C}$. The proteins $(20 \mu \mathrm{g})$ were loaded onto each lane, separated on $10 \%$ pre-cast SDS-PAGE gel (Invitrogen), and followed by transfer in the iBlot system (Thermo Scientific). The membranes were blocked with a bovine serum albumin solution (Sigma) for $1 \mathrm{~h}$ at room temperature and incubated with the following primary antibodies. The antibodies for KRAS (1:1000), phospho-ERK1/2 (1:2000), ERK1/2 (1:1000), AKT (1:1000), phospho-AKT (1:1000) and HSP90 (1:1000) were obtained from Cell Signaling Technology (Danvers, MA). The antibody for the $\beta$-actin $(1: 1000)$ was obtained from 
Sigma. The membranes were then incubated with horseradish peroxidase-conjugated goat anti-rabbit or anti-mouse antibodies for $2 \mathrm{~h}$ (Pierce, Rockford, IL, USA). The blots were detected by using a SuperSignal ${ }^{\circledR}$ West Femto enhancer kit (Pierce). Densitometry analysis was performed by using ImageJ (NIH, Bethesda, MD, USA). The ratios of KRAS/ $\beta$-actin, phospho-pERK/ERK, and phospho-AKT/AKT were calculated with the control representing 1.0-fold changes, which is shown below.

\subsection{Tumor Growth Analysis In Vivo}

The inhibitory effects of GSC on colorectal cancer growth were investigated in an animal model. Twenty-one 6-week-old BALB/c athymic nude mice (male) were obtained from the BioToxTech animal center (Cheongju, Korea). Animal care and handling procedures were performed in compliance with the experimental protocol approved by the Institutional Animal Care and Use Committee (IACUC) at Silla University (Busan, Korea). SW480 cells were harvested from the culture plate and re-suspended in PBS. A total of $5 \times 10^{6}$ cells in $0.1 \mathrm{~mL}$ of media were injected subcutaneously into both sides of nude mice [24]. When engrafted, the tumor volume was measured daily with calipers and calculated by using the following formula: $\mathrm{V}=\left(\mathrm{L} \times \mathrm{W}^{2}\right) / 2$, where $\mathrm{V}=$ volume, $\mathrm{L}=$ length, and $\mathrm{W}=$ width. When the tumors reached approximately $100 \mathrm{~mm}^{3}$ in size, the mice were assigned randomly to their respective treatments (Cetuximab, GSC extract, and saline control, $n=7 /$ group). The mice were treated twice per week with an intraperitoneal injection of $10 \mathrm{mg} / \mathrm{kg}$ Cetuximab in PBS. The GSC extracts were administered by an oral gavage ( $400 \mathrm{mg} / \mathrm{kg} /$ day) every day for 23 days.

\subsection{Statistical Analysis}

The data are expressed as the means \pm standard error of the mean (SEM). Statistical analyses were performed by one-way analysis of variance (ANOVA) using SPSS software, version 12 (SPSS Inc., Chicago, IL, USA). The differences were considered significant at $p<0.05$.

\section{Results}

\subsection{Proximate Composition and Analysis of Amino acids}

GSC consisted of 55\% crude protein, $13 \%$ crude ash, and less than $1 \%$ crude fat (Table 1). Table 2 lists the profiles of the amino acids in GSC. A total of 18 amino acids were analyzed. GSC contained all the essential amino acids (EAA), which are isoleucine (Ile), leucine (Leu), lysine (Lys), methionine (Met), phenylalanine (Phe), threonine (Thr), valine (Val), and tryptophan (Trp). Leucine and threonine were found at high levels. Non-essential amino acids (NEAA) of cysteine (Cys), aspartic acid (Asp), glycine (Gly), glutamic acid (Glu), alanine (Ala), serine (Ser), proline (Pro), and tyrosine (Tyr) were also found in GSC, with glutamic acid being the most abundant. Based on amino acid analysis, GSC contained high levels of delicious amino acids (DAA) including Glu, Asp, Gly, and Ala.

Table 1. Proximate composition of Cordyceps militaris on germinated soybeans (GSC).

\begin{tabular}{cc}
\hline Compound (\% of Lyophilisate) & \\
\hline Crude protein & 55 \\
Crude fat & 1 \\
Crude ash & 13 \\
\hline
\end{tabular}

\subsection{GSC Suppressed KRAS-Mutated Colorectal Cancer Cell Proliferation}

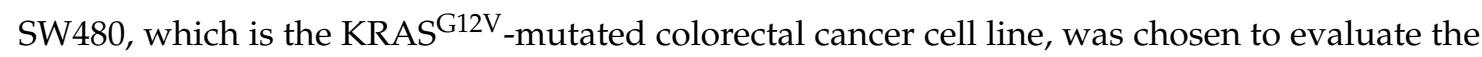
GSC antitumor potential. The cells were treated with GSC at different concentrations and Cetuximab as the drug control. Figure 1A presents SW480 colorectal cancer cell proliferation in the presence of GSC extracts at different concentrations $(0,1,10,100$, and $500 \mu \mathrm{g} / \mathrm{mL})$ on day 1 and 3 . The cell growth was calculated as the relative percentage absorbance compared to the control. As a result, treating SW480 
colon cancer cells with GSC suppressed cell proliferation in a dose-dependent manner when compared to the control. For example, the cell viability on day 3 was decreased by up to $54.2 \pm 2.95 \%$ with the $100 \mu \mathrm{g} / \mathrm{mL}$ GSC treatment and $40.0 \pm 2.2 \%$ with the $500 \mu \mathrm{g} / \mathrm{mL}$ GSC treatment. This led to the selection of doses for further mechanistic and molecular studies, which ranged from 1 to $500 \mu \mathrm{g} / \mathrm{mL}$. For morphological observations, the cells were stained with PI and DAPI under the GSC treatment (Figure 1B). Dead cells were stained with PI and were expressed as a red color. The cell nuclei from the dead and live cells were stained as DAPI (blue color). As shown in Figure 1B, most cells were only stained with blue DAPI in the control group, which showed that most cells were alive after $48 \mathrm{~h}$ of cultivation. On the other hand, the PI-stained dead cells began to appear and their ratios increased with a rise in the GSC concentration. In addition, the GSC extract fraction suppressed the proliferation on different types of KRAS mutations, e.g., LS513 (KRAS ${ }^{\mathrm{G} 12 \mathrm{D}}$ ), HCT116 (KRAS ${ }^{\mathrm{G} 13 \mathrm{D}}$ ), HT-29 (KRASWT / BRAF ${ }^{\text {Mut }}$ ), Caco-2 (KRASWT $/$ BRAF $^{W T}$ ) and A549 (KRASWT / BRAFWT) (Figure 1C). In the KRASWT / BRAF ${ }^{M u t}$ HT-29 CRC line, the GSC extract also inhibited the proliferation, but had less effect on the proliferation at the same concentration ranges $(1,10,100$, and $500 \mu \mathrm{g} / \mathrm{mL}$ ) (Figure 1C). As seen in Figure 1C, GSC did not show a suppressive effect on KRASWT /BRAF ${ }^{\mathrm{WT}}$ Caco-2 CRC and A549 lung cancer cell proliferation. The $\mathrm{IC}_{50}$ values on KRAS mutated CRC cell lines were $214 \mu \mathrm{g} / \mathrm{mL}$ (SW480), $493 \mu \mathrm{g} / \mathrm{mL}$ (LS513) and $441 \mu \mathrm{g} / \mathrm{mL}$ (HCT116) (Figure 1D). IC 50 of HT-29 increased up to approximately 10 -fold and $\mathrm{IC}_{50}$ of $\mathrm{KRAS}^{\mathrm{WT}} / \mathrm{BRAF}^{\mathrm{WT}}$ cells of Caco-2 and A549 was not applicable due to its minimal effect. Figure 1 demonstrated that KRAS-mutated CRC cell lines showed more sensitive responses under GSC treatment than the response of the KRAS wild-type cell line.

Table 2. Amino acid composition of GSC (mg/g).

\begin{tabular}{|c|c|}
\hline Amino Acids & Essential Amino Acids (EAA) \\
\hline Isoleucine & $0.76 \pm 0.00$ \\
\hline Leucine & $2.53 \pm 0.00$ \\
\hline Lysine & $1.94 \pm 0.17$ \\
\hline Methionine & $0.55 \pm 0.00$ \\
\hline Phenylalanine & $1.29 \pm 0.04$ \\
\hline Threonine & $3.06 \pm 0.09$ \\
\hline Valine & $2.21 \pm 0.06$ \\
\hline \multirow[t]{2}{*}{ Tryptophan } & $0.44 \pm 0.07$ \\
\hline & Half-Essential Amino Acids (HEAA) \\
\hline Arginine & $1.42 \pm 0.02$ \\
\hline \multirow[t]{2}{*}{ Histidine } & $0.76 \pm 0.17$ \\
\hline & Non-Essential Amino Acids (NEAA) \\
\hline Cysteine & $0.27 \pm 0.00$ \\
\hline Aspartic acid & $3.16 \pm 0.04$ \\
\hline Glycine & $1.81 \pm 0.03$ \\
\hline Glutamic acid & $16.40 \pm 0.32$ \\
\hline Alanine & $4.11 \pm 0.08$ \\
\hline Serine & $3.51 \pm 0.09$ \\
\hline Proline & $1.18 \pm 0.06$ \\
\hline \multirow[t]{2}{*}{ Tyrosine } & $1.50 \pm 0.06$ \\
\hline & Amino Acid Groups and Ratios \\
\hline Total amino acids (TAA) & $46.9 \pm 1.3$ \\
\hline Essential amino acids (EAA) & $12.78 \pm 0.43$ \\
\hline Half-essential amino acids (HEAA) & $2.18 \pm 0.19$ \\
\hline Non-essential amino acids (NEAA) & $31.94 \pm 0.68$ \\
\hline Delicious amino acids (DAA) & $25.48 \pm 0.47$ \\
\hline EAA/TAA & 0.27 \\
\hline EAA/NEAA & 0.40 \\
\hline DAA/TAA & 0.54 \\
\hline
\end{tabular}




\subsection{GSC Extract Alters Clonogenic Characteristics}

The clonogenic potential was evaluated to determine the long-term anti-proliferative activity of GSC on colorectal cancer cells. The colony-forming ability is one of the tumor cell characteristics and is tightly correlated with tumorigenes in vivo. As shown in Figure 2A, the SW480 colonies disappeared or could not be formed at the highest GSC concentration. A similar tendency was also observed on other KRAS mutant cells known as LS513 (KRAS ${ }^{\mathrm{G} 12 \mathrm{D}}$ ) and HCT116 (KRAS ${ }^{\mathrm{G} 13 \mathrm{D}}$ ). The clonogenic potential of SW480 was suppressed significantly by GSC in a dose-dependent manner when compared to the controls (Figure 2B). For example, the colony numbers were reduced by up to $72 \pm 10 \%$ and $16 \pm 8 \%$ after 100 and $500 \mu \mathrm{g} / \mathrm{mL}$ GSC treatment, respectively. In particular, the reductions in the colony number were accompanied by reductions of the colony size. Under Cetuximab treatment, the colony numbers were $93 \pm 3 \%$, which might indicate a cell resistant property to the drug in long-term incubation. In case of KRAS wild-type cells, the clonogenic potential was suppressed by GSC treatment. However, this was relatively low compared to the KRAS-mutated group. These findings suggest that the treatment of colorectal cancer cells with GSC would decrease their rate of proliferation and their tumor-formation ability.

A

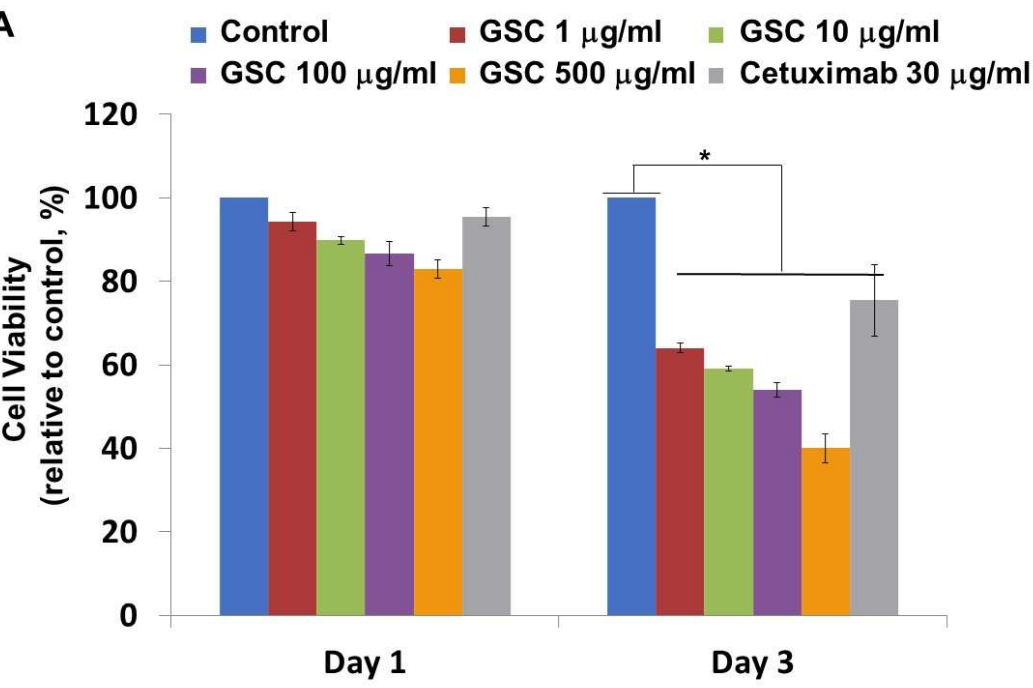

B
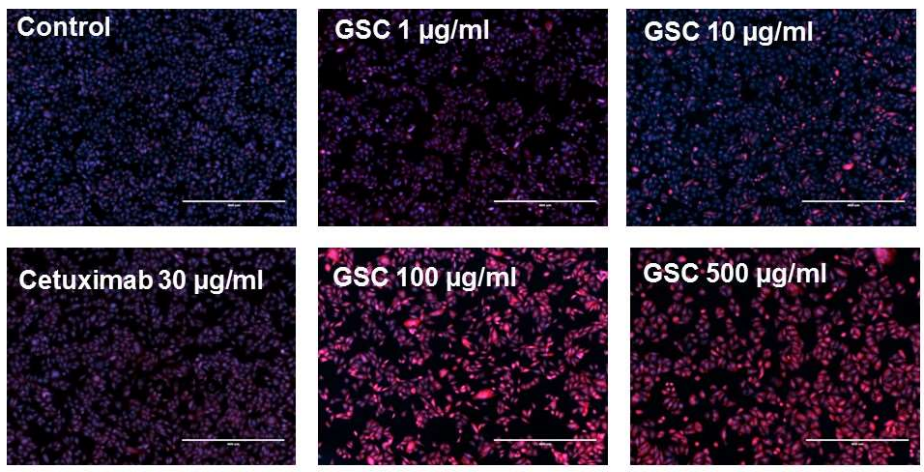

$6 s \mathrm{c} .500 \mathrm{\mu g} / \mathrm{ml}$

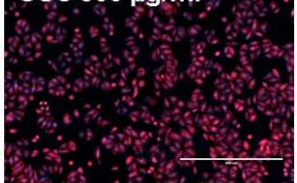

Figure 1. Cont. 

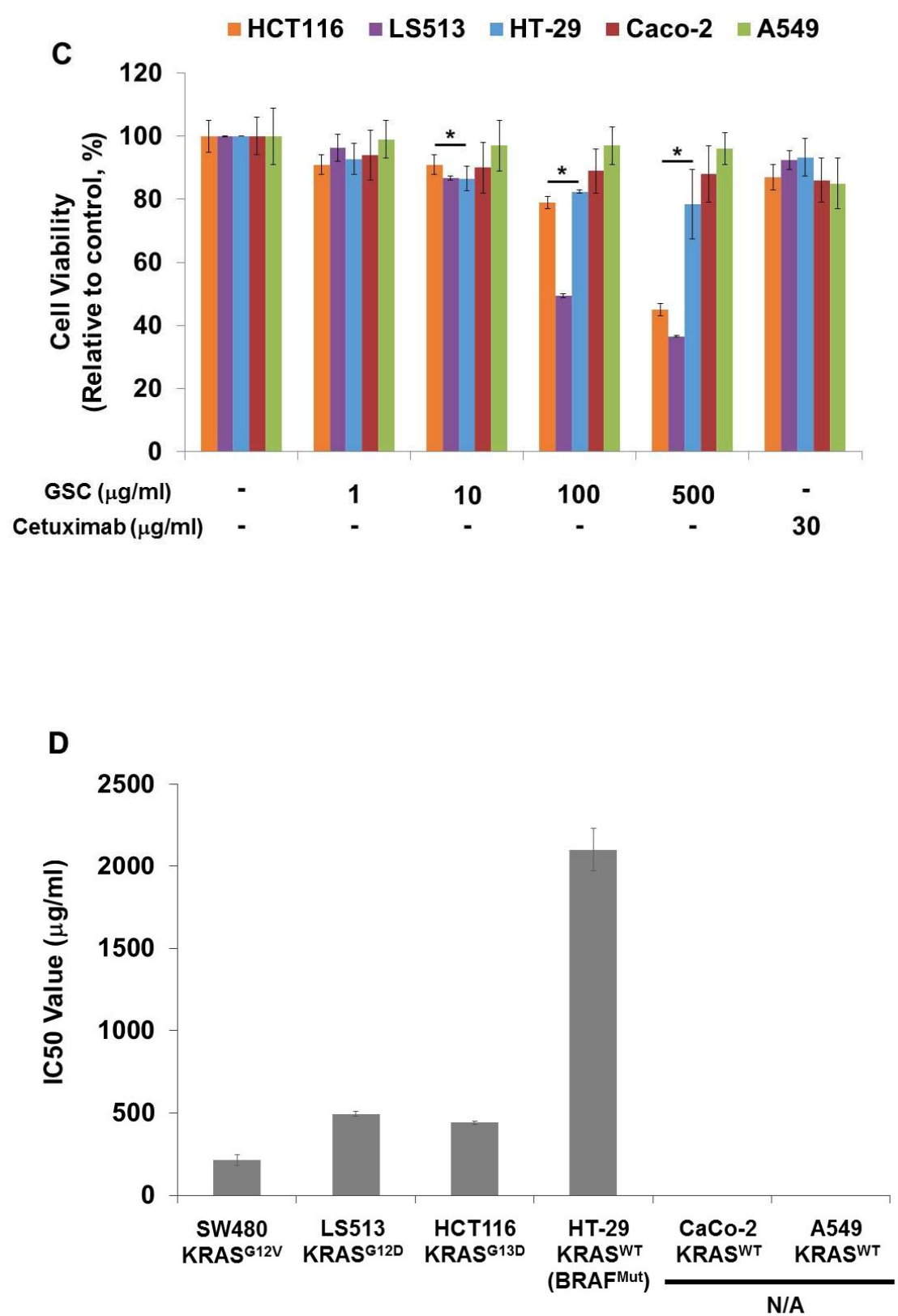

Figure 1. (A) Cell viability of SW480 colorectal cancer cells at days 1 and 3 with the GSC treatment $(0,1$, 10,100 , and $500 \mu \mathrm{g} / \mathrm{mL}$ ). The relative cell viability was compared to the control. The data are expressed as the mean \pm standard error of the mean (SEM) and a significant difference is denoted as * $(p<0.05)$. (B) Representative SW480 cell images after the GSC treatment $(0,1,10,100$ and $500 \mu \mathrm{g} / \mathrm{mL})$. Blue represents the DAPI-stained cell nuclei and the propidium iodide-stained dead cells are red. (Scale bar $=500 \mu \mathrm{m})$. (C) Cell viability of LS513 (Kirsten rat sarcoma viral oncogene homolog (KRAS) ${ }^{\mathrm{G} 12 \mathrm{D}}$ ), HCT116 (KRAS ${ }^{\mathrm{G} 13 \mathrm{D}}$ ), HT-29 (KRAS $\left.{ }^{\mathrm{WT}} / \mathrm{BRAF}^{\mathrm{Mut}}\right)$, Caco-2 (KRAS ${ }^{\mathrm{WT}} / \mathrm{BRAF}^{\mathrm{WT}}$ ) and A549 (KRAS ${ }^{\mathrm{WT}} / \mathrm{BRAF}^{\mathrm{WT}}$ ) during day 3 with GSC $(0,1,10,100$, and $500 \mu \mathrm{g} / \mathrm{mL})$ and Cetuximab $(30 \mu \mathrm{g} / \mathrm{mL})$ treatment. The relative cell viability was compared with the control. (D) IC 50 values of SW480 (KRAS ${ }^{\mathrm{G} 12 \mathrm{~V}}$ ), LS513 (KRAS ${ }^{\mathrm{G} 12 \mathrm{D}}$ ), HCT116 $\left(\mathrm{KRAS}^{\mathrm{G} 13 \mathrm{D}}\right)$, HT-29 (KRAS $\left.{ }^{\mathrm{WT}} / \mathrm{BRAF}^{\mathrm{Mut}}\right), \mathrm{Caco}-2\left(\mathrm{KRAS}^{\mathrm{WT}} / \mathrm{BRAF}^{\mathrm{WT}}\right)$ and A549 $\left(\mathrm{KRAS}^{\mathrm{WT}} / \mathrm{BRAF}^{\mathrm{WT}}\right.$ ) cell lines at day 3 under GSC treatment. The data are expressed as the mean standard error of the mean (SEM) and a significant difference is denoted as * $(p<0.05)$ compared to control. GSC: Cordyceps militaris on germinated soybeans. DAPI, $4^{\prime}$,6-diamidino-2-phenylindole. 
A

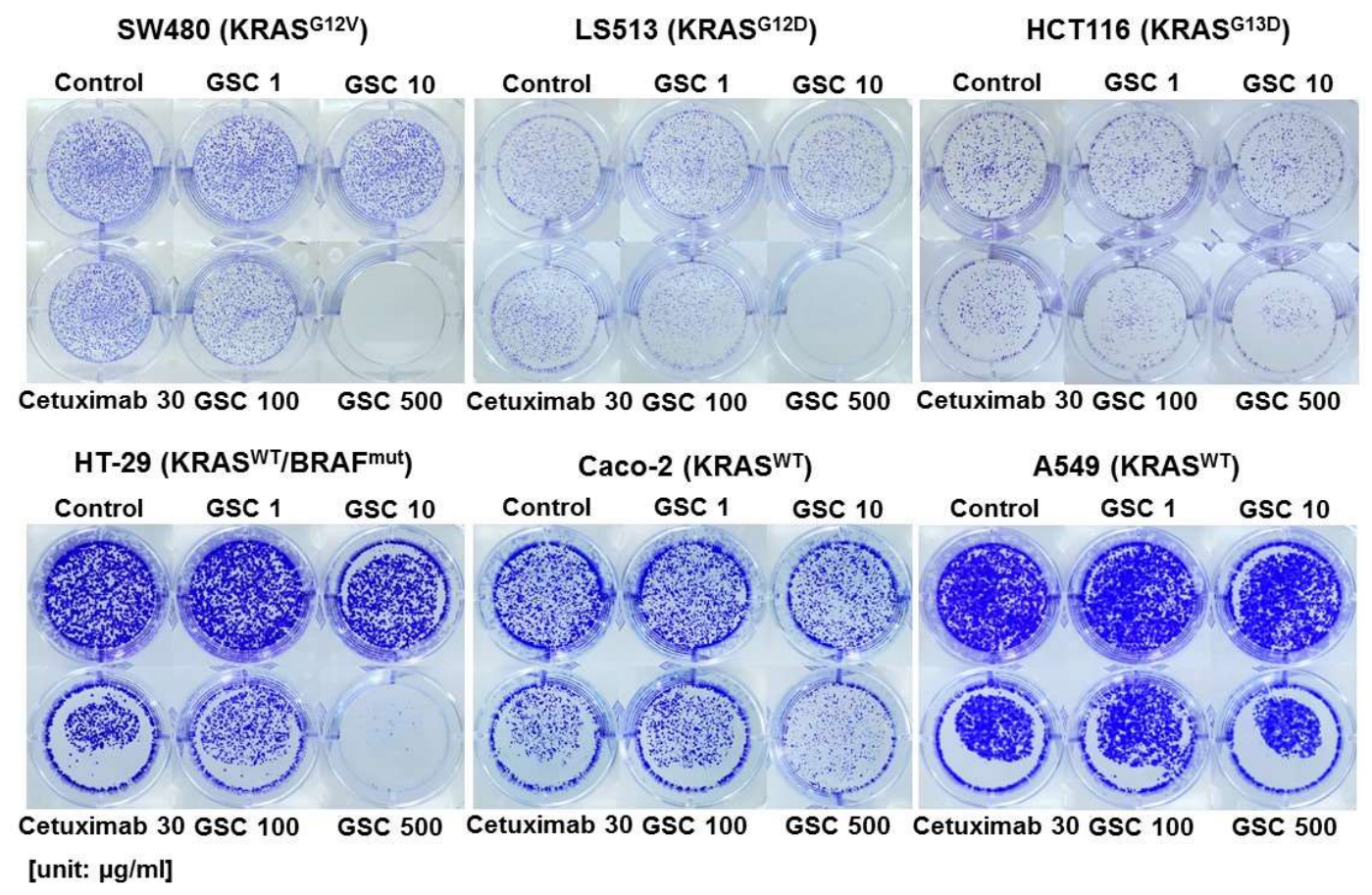

B

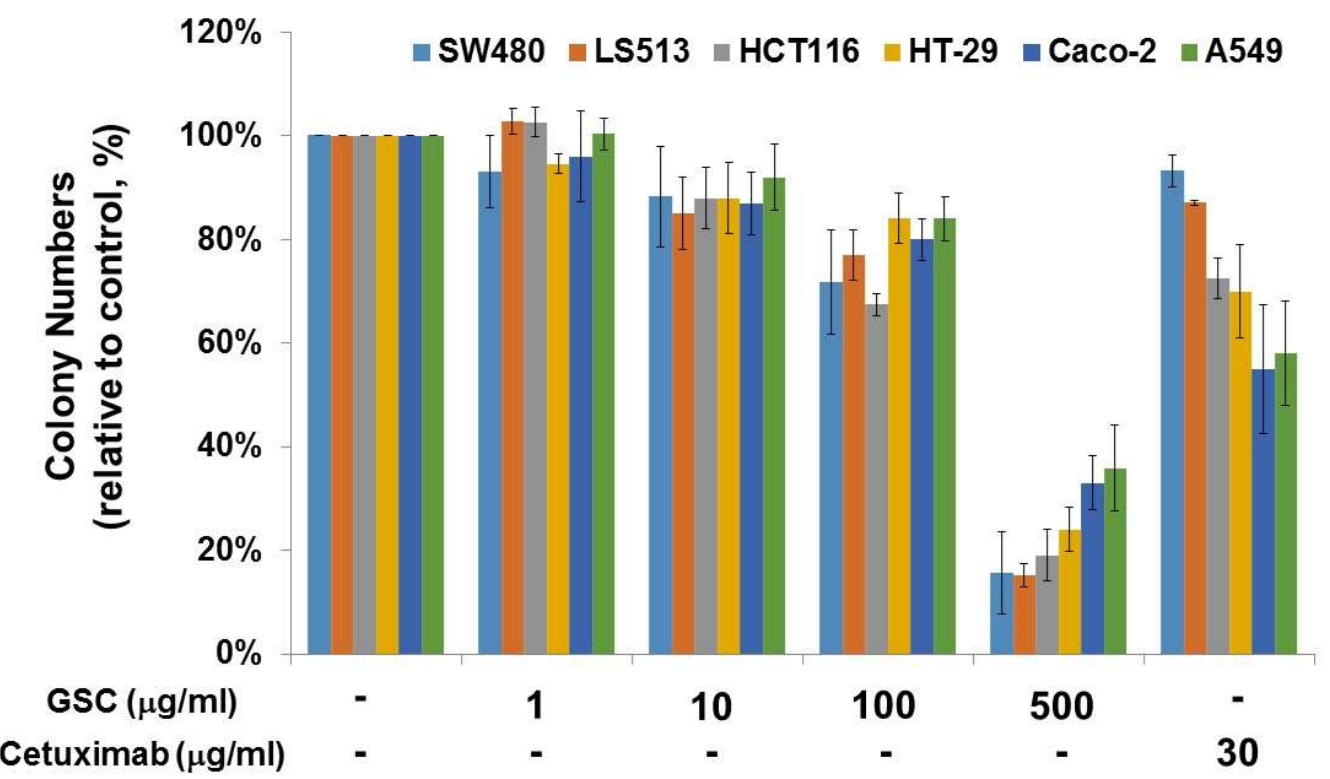

Figure 2. (A) Clonogenic potential after the GSC extract treatment $(0,1,10,100$, and $500 \mu \mathrm{g} / \mathrm{mL})$ on day 10 on SW480 (KRAS ${ }^{\mathrm{G} 12 \mathrm{~V}}$ ), LS513 (KRAS ${ }^{\mathrm{G} 12 \mathrm{D}}$ ), HCT116 (KRAS ${ }^{\mathrm{G} 13 \mathrm{D}}$ ), HT-29 (KRAS ${ }^{\mathrm{WT}} / \mathrm{BRAF}^{\mathrm{Mut}}$ ), Caco-2 $\left(\mathrm{KRAS}^{\mathrm{WT}} / \mathrm{BRAF}^{\mathrm{WT}}\right.$ ) and A549 $\left(\mathrm{KRAS}^{\mathrm{WT}} / \mathrm{BRAF}^{\mathrm{WT}}\right)$. (B) Relative colony numbers upon the GSC treatment on SW480 (KRAS ${ }^{\mathrm{G} 12 \mathrm{~V}}$ ), LS513 (KRAS ${ }^{\mathrm{G} 12 \mathrm{D}}$ ), HCT116 (KRAS ${ }^{\mathrm{G} 13 \mathrm{D}}$ ), HT-29 (KRAS ${ }^{\mathrm{WT}} / \mathrm{BRAF}^{\mathrm{Mut}}$ ), Caco-2 $\left(\mathrm{KRAS}^{\mathrm{WT}} / \mathrm{BRAF}^{\mathrm{WT}}\right)$ and $\mathrm{A} 549\left(\mathrm{KRAS}^{\mathrm{WT}} / \mathrm{BRAF}^{\mathrm{WT}}\right)$. The data are expressed as the mean \pm standard error of the mean (SEM). GSC: Cordyceps militaris on germinated soybeans. 


\subsection{GSC Extract-Induced KRAS-Driven Colorectal Cancer Cell Apoptosis}

Annexin V-FITC/PI staining and flow cytometry were performed to examine GSC effects on cell death (Figure 3). Flow cytometry (FACS) analysis indicated that the GSC extract induced apoptosis in a concentration-dependent manner. For example, the GSC treatment $(10 \mu \mathrm{g} / \mathrm{mL})$ induced early (annexin $\mathrm{V} \mathrm{FITC}^{+} / \mathrm{PI}^{-}$) and late (annexin $\mathrm{V} \mathrm{FITC}^{+} / \mathrm{PI}^{+}$) apoptosis of $20.9 \pm 0.23 \%$. The apoptotic rate increased to $56.3 \pm 6.07 \%$ and $72.3 \pm 1.64 \%$ with 100 and $500 \mu \mathrm{g} / \mathrm{mL}$, respectively.

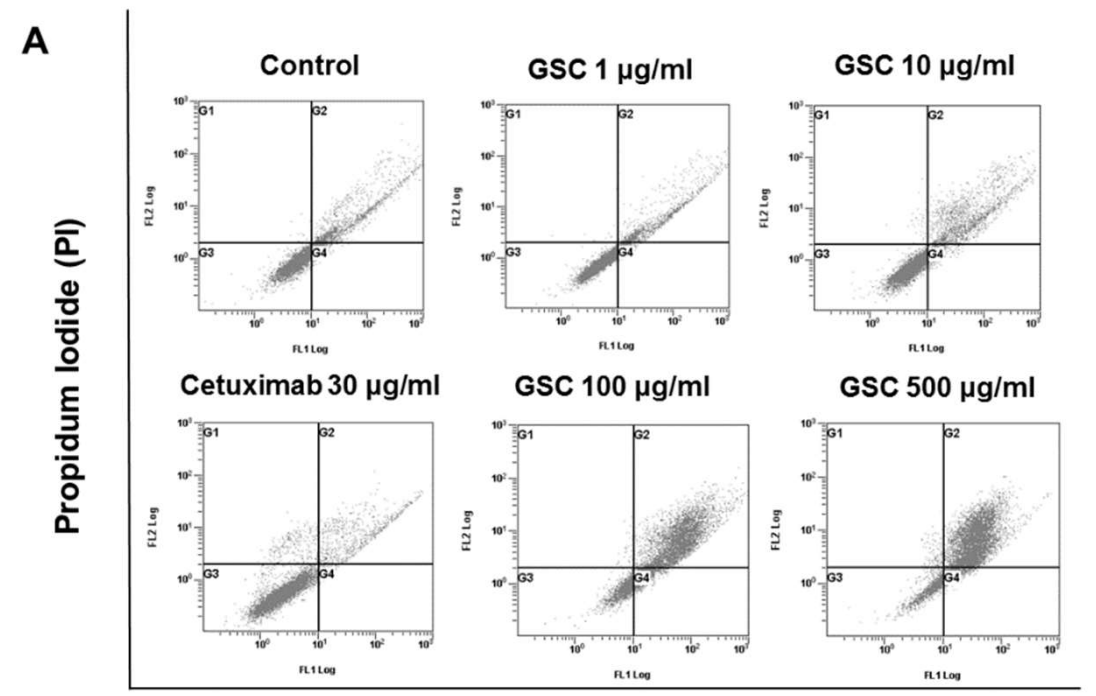

Annexin V-FITC

B

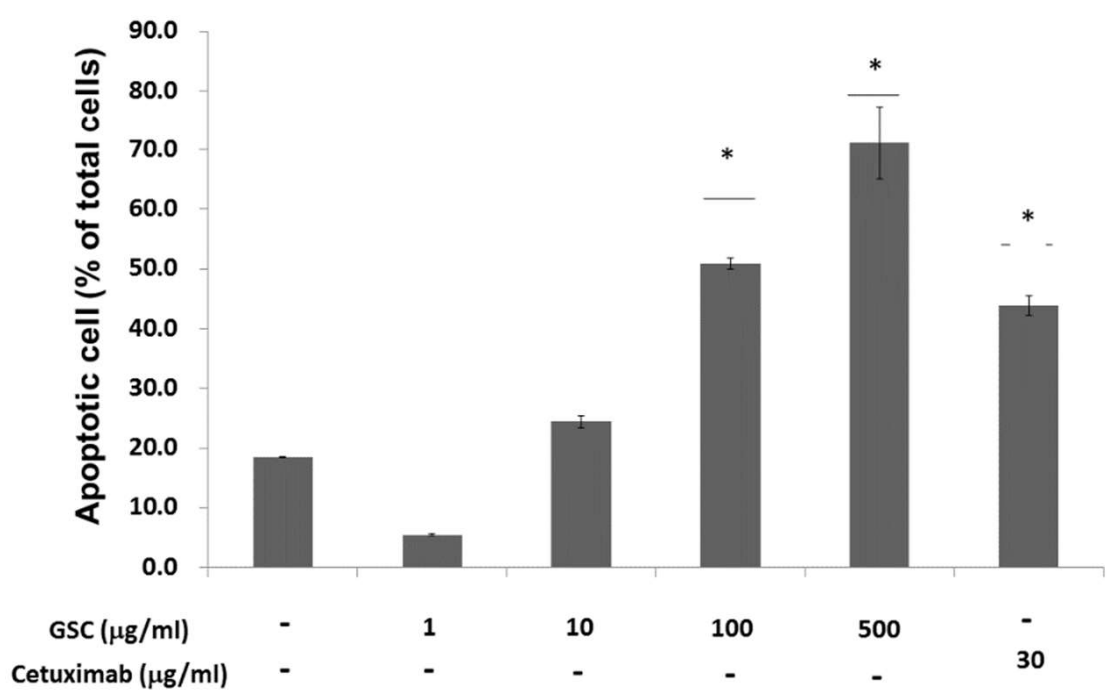

Figure 3. (A) Flow cytometry plots using Annexin V-FITC/PI staining for apoptosis. SW480 cells were treated for $24 \mathrm{~h}$ and then stained with Annexin V-FITC/PI upon GSC treatment $(0,1,10,100$, and $500 \mu \mathrm{g} / \mathrm{mL}$ ). (B) The percentage of apoptotic cells upon the GSC treatment were compared statistically and the significant differences are denoted by $*(p<0.05)$. GSC: Cordyceps militaris on germinated soybeans, FITC, fluorescein isothiocyanate, PI, propidium iodide. The data are expressed as the mean \pm standard error of the mean (SEM).

\subsection{Effects of GSC Extract on the RAS/ERK Signaling Pathways}

KRAS-mutated colorectal cancer is related to the RAS/ERK or PI3K/AKT pathways. On CRC progression, mutated KRAS proteins are produced continuously, which activate ERK-mediated 
transcriptional up-regulation. To determine if the suppression of SW480 growth by GSC was regulated by the RAS/ERK pathways, the cells were treated with GSC for $48 \mathrm{~h}$. In addition, the expression levels of the KRAS, p-ERK, ERK, p-AKT, and AKT proteins were analyzed by Western blot. As shown in Figure 4A,B, the GSC treatment significantly suppressed KRAS expression and ERK phosphorylation. The GSC treatment decreased ERK phosphorylation significantly in a concentration-dependent manner. For example, the ratio of pERK/ERK in the control (1.00 \pm 0.00$)$ was reduced up to $0.44 \pm 0.13$ in the GSC $500 \mu \mathrm{g} / \mathrm{mL}$-treated group. An alternative downstream of KRAS, which is the PI3K/AKT pathway, was also observed. The level of AKT phosphorylation was similar in all samples to that observed with the pAKT/AKT ratio. Based on the result, the GSC treatment suppressed colon cancer progression, which was mostly mediated by the RAS/ERK signaling pathway.

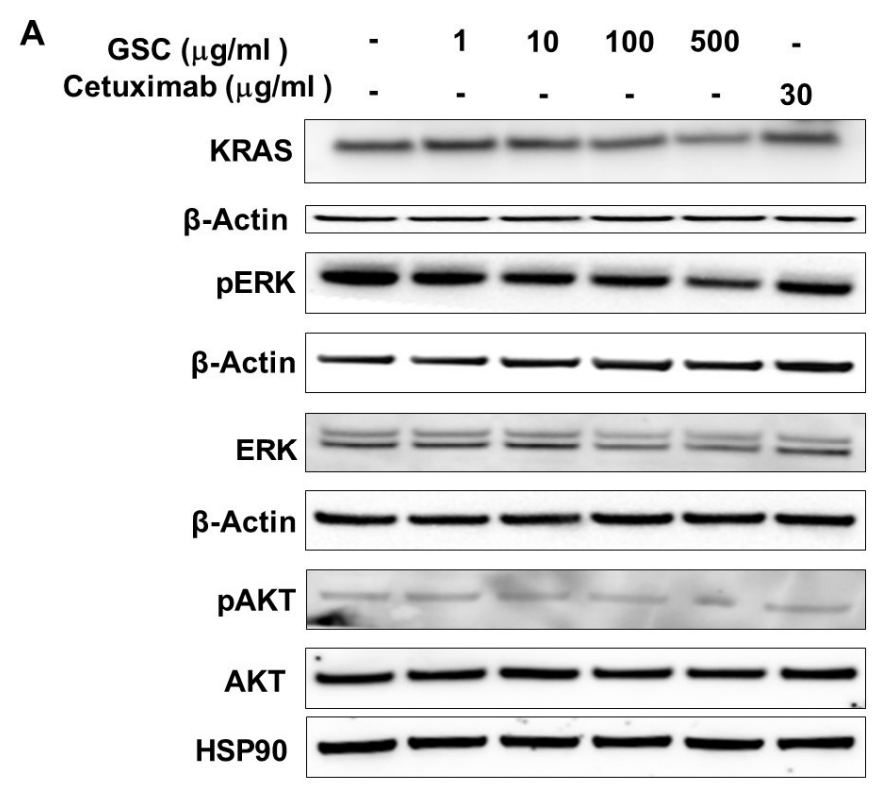

B

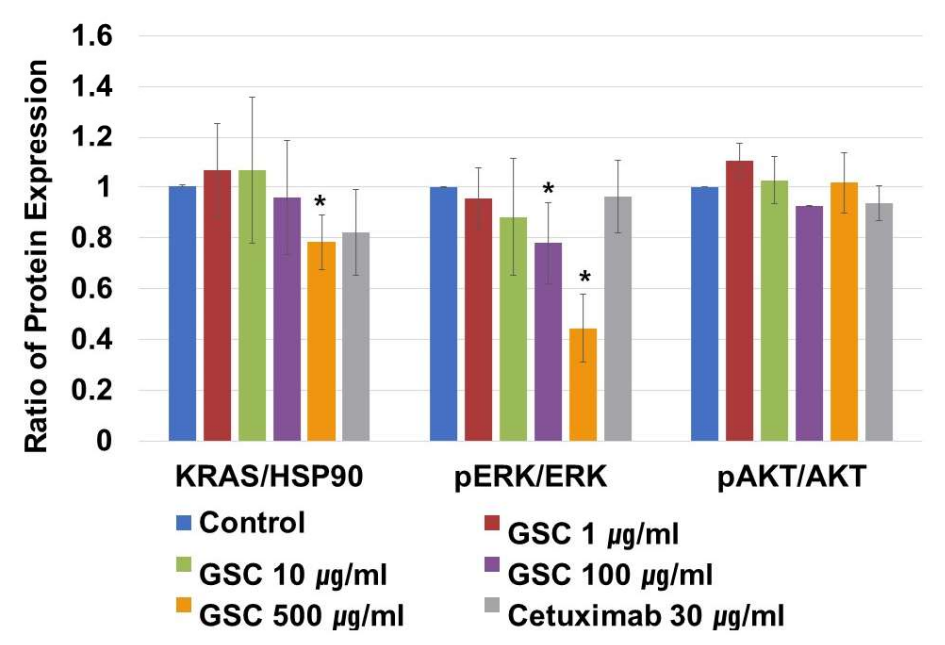

Figure 4. (A) Representative western blot images of KRAS, $\beta$-actin, phospho-p42/44 MAPK (phospho-ERK1/2), p42/44 MAPK (ERK1/2), phospho-AKT/AKT and HSP90 protein expression in SW480 cells treated with the GSC extract $(0,1,10,100$, and $500 \mu \mathrm{g} / \mathrm{mL})$. (B) The protein intensity was analyzed in triplicate. The ratios of KRAS/ $\beta$-actin, phospho-p42/44/p42/44, and phospho-AKT/AKT were calculated. The ratios were compared with the no treatment group and significant differences are denoted by ${ }^{*}(p<0.05)$. The data are expressed as the mean \pm standard error of the mean (SEM). 


\subsection{The GSC Extract Inhibits Tumor Growth in a Xenograft Colorectal Cancer Model}

To investigate whether the GSC extract inhibits tumor progression, the SW480 xenograft animal model was generated. Tumor formation was induced by injecting SW480 cells and administering GSC daily. As shown in Figure 5, GSC suppressed tumor growth, which was confirmed by the significant decrease in tumor volume compared to the PBS control (PBS control vs. GSC extracts, mean tumor volume on day $26=3724 \pm 714 \mathrm{~mm}^{3}$ vs. $2231 \pm 581 \mathrm{~mm}^{3}$ ). No significant anti-cancer activity was observed in the Cetuximab control group. The body weights of the mice showed no significant changes in all groups, which suggests that GSC feeding is safe and well-tolerated.

\section{A}

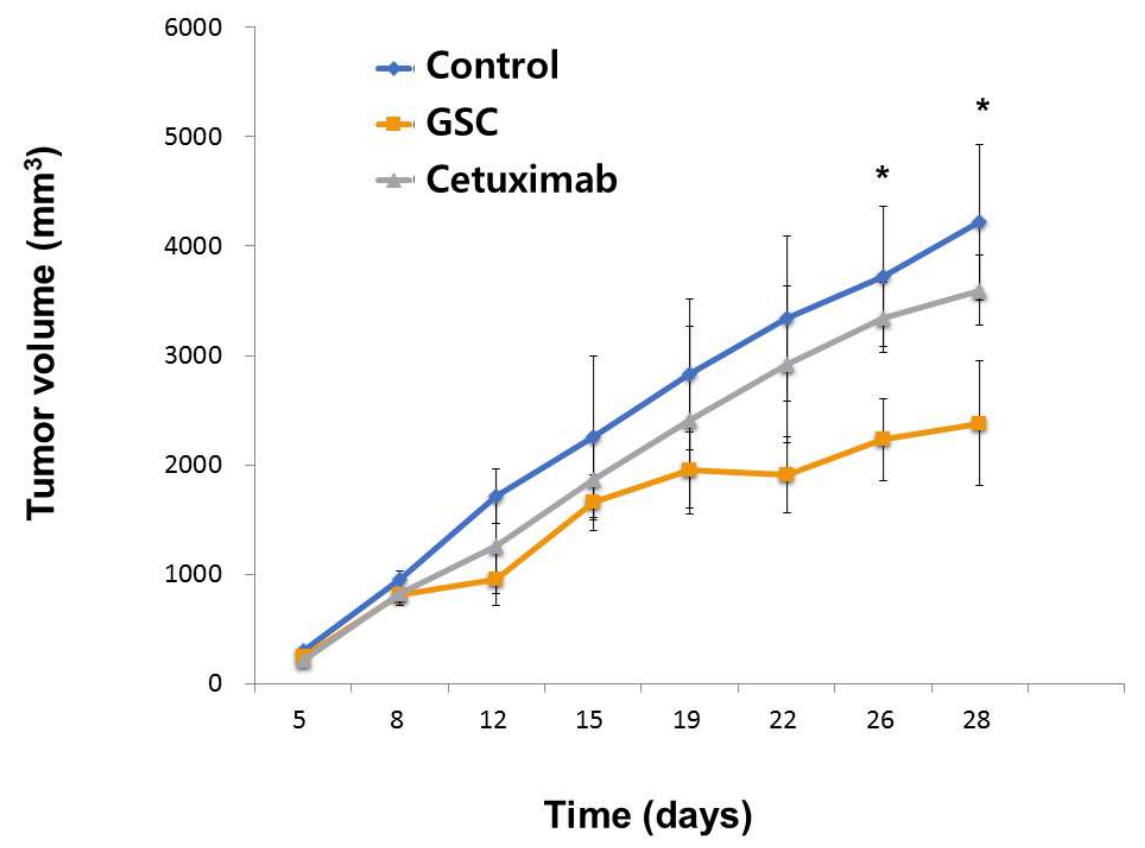

B

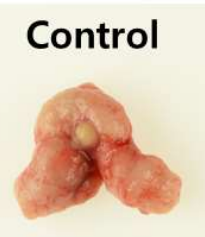

GSC

Cetuximab

Figure 5. (A) Tumor volume changes in SW480 xenograft mice treated with the control (PBS), Cetuximab (10 mg/ kg in PBS) and GSC extract ( $400 \mathrm{mg} / \mathrm{kg} /$ day) $(n=7)$. The tumor volumes were compared with those of the control treatment and a significant difference is denoted as $*(p<0.05)$. (B) Representative SW480 xenograft tumors were resected on day 26 showing the difference in tumor volume between the control or the Cetuximab treatment and the GSC extract treatment. Scale bar $=1 \mathrm{~cm}$. The data are expressed as the mean \pm standard error of the mean (SEM).

\section{Discussion}

Colorectal cancer (CRC) is the third most prevalent cancer and is becoming the leading cause of cancer death [1,2]. In recent years, attempts to improve the survival rates in CRC have focused on innovative therapeutic methods including EGF-receptor antibody therapy such as Cetuximab [4]. On the other hand, $30 \%$ to $40 \%$ of patients with KRAS-mutated colorectal cancer do not benefit from 
Cetuximab therapy [5-7]. Natural compounds could be an attractive option for cancer therapy as a result of their safety and their applications. GSC has therapeutic activity for inflammatory conditions, allergies, and cancer. The current study showed that GSC treatment could suppress KRAS-driven colon cancer both in vitro and in vivo. GSC showed enhanced antitumor activity based on the results of cell proliferation and clonogenic potential in multiple KRAS-mutated colorectal cancer cells such as SW480 (KRAS ${ }^{\mathrm{G} 12 \mathrm{~V}}$ ), LS513 (KRAS ${ }^{\mathrm{G} 12 \mathrm{D}}$ ) and HCT116 (KRAS ${ }^{\mathrm{G} 13 \mathrm{D}}$ ) (Figure 1). A less than 50\% growth rate on KRAS-mutated CRC cell lines of SW480, LS513, and HCT116 was observed. In the KRAS ${ }^{W T}$ cell line of HT-29, Caco-2 and A549 cell proliferation was approximately 80\%, which indicated that GSC is more effective on KRAS-mutated colon cancer (Figure 1). Clonogenic potential showed a similar tendency. KRAS-mutated cell lines showed significant suppression on the clonogenic potential (Figure 2). KRAS-mutated cell death was from the increasing apoptosis with GSC treatment (Figure 3). The RAS/ERK pathway study suggested that GSC could show an antitumor effect through the modulation of the ERK pathway by altering the phosphorylation of ERK (Figure 4). In a human tumor growth model, the growth of KRAS mutant xenograft tumors was suppressed significantly by the GSC treatment (Figure 5).

The RAS/ERK signaling pathway and its downstream factors are recognized as key regulators for cellular behaviors including cell survival, proliferation, invasion, and migration [3]. During CRC progression, mutant RAS constitutively activates ERK phosphorylation. Therefore, this study examined their changes upon the GSC treatment and found decreased KRAS expression and phosphorylation of ERK proteins in SW480 cells (Figure 3).

Cordyceps militaris on germinated soybeans contains several bioactive compounds. In particular, isoflavone methyl-glycosides, cordycepin, adenine, and adenosine have been identified $[19,20]$. Four isoflavone methyl-glycosides including daidzein 7-O-b-D-glucoside $4^{\prime \prime}$-O-methylate, glycitein 7-O-b-D-glucoside $4^{\prime \prime}-\mathrm{O}$-methylate, genistein 7-O-b-D-glucoside $4^{\prime \prime}$-O-methylate, and genistein $4^{\prime}$-O-b-D-glucoside $4^{\prime \prime}$-O-methylatewere identified to exhibit anti-allergic activity in antigen-stimulated mast cells by suppressing ERK phosphorylation [19,21]. Genistein induced apoptosis on leukemia and colon cancer and inhibited breast cancer cell proliferation $[25,26]$. Cordycepin (a nucleoside derivative), which is a major active component of GSC, induces apoptosis in melanoma and lung carcinoma $[27,28]$. Furthermore, adenosine from GSC suppressed the growth of human gastric cancer cells significantly and the adenosine receptor 1 suppressed colon cancer proliferation [29]. The anti-tumor effects of GSC might come from the above functional compounds within the GSC.

In our current study, GSC contains relatively low Met $0.55 \mathrm{mg} / \mathrm{g}$ and high Arg $1.42 \mathrm{mg} / \mathrm{g}$ crude (Table 2). Several studies have examined the effects of individual amino acids such as Met, Ser, Gly, and Arg on cancer progression. Met restriction was reported to inhibit cancer cell growth and to extend a healthy lifespan in several animal studies [30]. Met-depletion in cancer cells was reported to lead to cell cycle arrest. Deprivation of dietary Ser and Gly inhibits the growth of tumors by limiting nucleotide biosynthesis [31]. When Arg was provided at $1 \mathrm{mmol} / \mathrm{L}$, it suppressed colon cancer by lowering the angiogenesis-related growth factors [32,33]. Relatively low Met $0.55 \mathrm{mg} / \mathrm{g}$ and high Arg $1.42 \mathrm{mg} / \mathrm{g}$ crude might play roles in suppressing colon cancer.

\section{Conclusions}

In conclusion, these observations suggest that GSC suppressed CRC progression with inhibitory effects, stopping the essential steps of tumor growth. GSC may be a powerful candidate for the development of a preventive agent for cancer growth. To the best of the authors' knowledge, this is the first study reporting that a GSC treatment suppresses KRAS-mutated colon cancer through the ERK-dependent pathways. Given the non-toxic nature of these natural food substances and their beneficial activities, these results provide support for the incorporation of the GSC extract into therapeutic regimens for colorectal cancer.

Author Contributions: H.S. performed the experiments; M.K. analyzed the data; J.S. did the animal experiments; D.-W.H. discussed the results; H.-J.P. designed the experiments; M.S. wrote the manuscript. 
Funding: This research was funded by National Research Foundation of Korea (NRF-2016R1A1A1A05921948, 2016R1D1A1B03931076) and the Korea Health Technology R\&D Project through the Korea Health Industry Development Institute (KHIDI) (HI17C1662). The APC was funded by NRF-2016R1A1A1A05921948.

Acknowledgments: The author would like to thank Dong Ki Park from the Cell Activation Research Institute, Seoul, Korea, for their technical support.

Conflicts of Interest: The authors declare no conflict of interest.

\section{References}

1. Global Burden of Disease Cancer Collaboration; Fitzmaurice, C.; Akinyemiju, T.F.; Al Lami, F.H.; Alam, T.; Alizadeh-Navaei, R.; Allen, C.; Alsharif, U.; Alvis-Guzman, N.; Amini, E.; et al. Global, Regional, and National Cancer Incidence, Mortality, Years of Life Lost, Years Lived With Disability, and Disability-Adjusted Life-Years for 29 Cancer Groups, 1990 to 2016: A Systematic Analysis for the Global Burden of Disease Study. JMMA Oncol. 2018, 4, 1553-1568. [CrossRef]

2. McCormick, F. KRAS as a Therapeutic Target. Clin. Cancer Res. 2015, 21, 1797-1801. [CrossRef]

3. Lee, S.K.; Hwang, J.H.; Choi, K.Y. Interaction of the Wnt/beta-catenin and RAS-ERK pathways involving co-stabilization of both beta-catenin and RAS plays important roles in the colorectal tumorigenesis. Adv. Biol. Regul. 2018, 68, 46-54. [CrossRef] [PubMed]

4. Van Cutsem, E.; Kohne, C.H.; Hitre, E.; Zaluski, J.; Chang Chien, C.R.; Makhson, A.; D’Haens, G.; Pinter, T.; Lim, R.; Bodoky, G.; et al. Cetuximab and chemotherapy as initial treatment for metastatic colorectal cancer. N. Engl. J. Med. 2009, 360, 1408-1417. [CrossRef] [PubMed]

5. De Roock, W.; Claes, B.; Bernasconi, D.; De Schutter, J.; Biesmans, B.; Fountzilas, G.; Kalogeras, K.T.; Kotoula, V.; Papamichael, D.; Laurent-Puig, P.; et al. Effects of KRAS, BRAF, NRAS, and PIK3CA mutations on the efficacy of cetuximab plus chemotherapy in chemotherapy-refractory metastatic colorectal cancer: A retrospective consortium analysis. Lancet Oncol. 2010, 11, 753-762. [CrossRef]

6. Lievre, A.; Bachet, J.B.; Le Corre, D.; Boige, V.; Landi, B.; Emile, J.F.; Cote, J.F.; Tomasic, G.; Penna, C.; Ducreux, M.; et al. KRAS mutation status is predictive of response to cetuximab therapy in colorectal cancer. Cancer Res. 2006, 66, 3992-3995. [CrossRef] [PubMed]

7. Bardelli, A.; Siena, S. Molecular mechanisms of resistance to cetuximab and panitumumab in colorectal cancer. J. Clin. Oncol. 2010, 28, 1254-1261. [CrossRef]

8. Normanno, N.; Morabito, A.; De Luca, A.; Piccirillo, M.C.; Gallo, M.; Maiello, M.R.; Perrone, F. Target-based therapies in breast cancer: Current status and future perspectives. Endocr. Relat. Cancer 2009, 16, 675-702. [CrossRef]

9. Misale, S.; Yaeger, R.; Hobor, S.; Scala, E.; Janakiraman, M.; Liska, D.; Valtorta, E.; Schiavo, R.; Buscarino, M.; Siravegna, G.; et al. Emergence of KRAS mutations and acquired resistance to anti-EGFR therapy in colorectal cancer. Nature 2012, 486, 532-536. [CrossRef]

10. Attoub, S.; Arafat, K.; Khalaf, T.; Sulaiman, S.; Iratni, R. Frondoside A enhances the anti-cancer effects of oxaliplatin and 5-fluorouracil on colon cancer cells. Nutrients 2018, 10, 560. [CrossRef]

11. Mi, C.; Ma, J.; Wang, K.S.; Zuo, H.X.; Wang, Z.; Li, M.Y.; Piao, L.X.; Xu, G.H.; Li, X.; Quan, Z.S.; et al. Imperatorin suppresses proliferation and angiogenesis of human colon cancer cell by targeting HIF-1alpha via the mTOR/p70S6K/4E-BP1 and MAPK pathways. J. Ethnopharmacol. 2017, 203, 27-38. [CrossRef] [PubMed]

12. Han, S.; Jeong, A.J.; Yang, H.; Bin Kang, K.; Lee, H.; Yi, E.H.; Kim, B.H.; Cho, C.H.; Chung, J.W.; Sung, S.H.; et al. Ginsenoside 20(S)-Rh2 exerts anti-cancer activity through targeting IL-6-induced JAK2/STAT3 pathway in human colorectal cancer cells. J. Ethnopharmacol. 2016, 194, 83-90. [CrossRef] [PubMed]

13. Yeh, C.C.; Lin, C.C.; Wang, S.D.; Hung, C.M.; Yeh, M.H.; Liu, C.J.; Kao, S.T. Protective and immunomodulatory effect of Gingyo-san in a murine model of acute lung inflammation. J. Ethnopharmacol. 2007, 111, 418-426. [CrossRef] [PubMed]

14. Paterson, R.R. Cordyceps: A traditional Chinese medicine and another fungal therapeutic biofactory? Phytochemistry 2008, 69, 1469-1495. [CrossRef] [PubMed]

15. Ng, T.B.; Wang, H.X. Pharmacological actions of Cordyceps, a prized folk medicine. J. Pharm. Pharmacol. 2005, 57, 1509-1519. [CrossRef] [PubMed] 
16. Won, S.Y.; Park, E.H. Anti-inflammatory and related pharmacological activities of cultured mycelia and fruiting bodies of Cordyceps militaris. J. Ethnopharmacol. 2005, 96, 555-561. [CrossRef] [PubMed]

17. Sung, J.M.; Park, Y.J.; Lee, J.O.; Han, S.K.; Lee, W.H.; Choi, S.K.; Shrestha, B. Effect of Preservation Periods and Subcultures on Fruiting Body Formation of Cordyceps militaris In Vitro. Mycobiology 2006, 34, 196-199. [CrossRef] [PubMed]

18. Park, D.K.; Park, H.J. Ethanol extract of Cordyceps militaris grown on germinated soybeans attenuates dextran-sodium-sulfate-(DSS-) induced colitis by suppressing the expression of matrix metalloproteinases and inflammatory mediators. Biomed. Res. Int. 2013, 2013, 102918. [CrossRef]

19. Park, D.K.; Choi, W.S.; Park, H.J. Antiallergic activity of novel isoflavone methyl-glycosides from Cordyceps militaris grown on germinated soybeans in antigen-stimulated mast cells. J. Agric. Food Chem. 2012, 60, 2309-2315. [CrossRef]

20. Park, H.J. Ethanol extract of Cordyceps militaris grown on germinated soybeans inhibits 2, 4-dinitrophenolfluorobenzene-induced allergic contact dermatitis. J. Funct. Foods 2015, 17, $938-947$. [CrossRef]

21. Han, J.Y.; Im, J.; Choi, J.N.; Lee, C.H.; Park, H.J.; Park, D.K.; Yun, C.H.; Han, S.H. Induction of IL-8 expression by Cordyceps militaris grown on germinated soybeans through lipid rafts formation and signaling pathways via ERK and JNK in A549 cells. J. Ethnopharmacol. 2010, 127, 55-61. [CrossRef] [PubMed]

22. Official Methods of Analysis of AOAC International. Oil in Cereal Adjuncts: Petroleum Ether Extraction Method, 17th ed.; Method 945.16; AOAC International: Gaithersburg, MD, USA, 2000.

23. Franken, N.A.; Rodermond, H.M.; Stap, J.; Haveman, J.; Van Bree, C. Clonogenic assay of cells in vitro. Nat. Protoc. 2006, 1, 2315-2319. [CrossRef]

24. Han, E.S.; Oh, J.Y.; Park, H.J. Cordyceps militaris extract suppresses dextran sodium sulfate-induced acute colitis in mice and production of inflammatory mediators from macrophages and mast cells. J. Ethnopharmacol. 2011, 134, 703-710. [CrossRef] [PubMed]

25. Pan, H.; Zhou, W.; He, W.; Liu, X.; Ding, Q.; Ling, L.; Zha, X.; Wang, S. Genistein inhibits MDA-MB-231 triple-negative breast cancer cell growth by inhibiting NF-kappaB activity via the Notch-1 pathway. Int. J. Mol. Med. 2012, 30, 337-343. [CrossRef] [PubMed]

26. Zhang, Z.; Wang, C.Z.; Du, G.J.; Qi, L.W.; Calway, T.; He, T.C.; Du, W.; Yuan, C.S. Genistein induces G2/M cell cycle arrest and apoptosis via ATM/p53-dependent pathway in human colon cancer cells. Int. J. Oncol. 2013, 43, 289-296. [CrossRef] [PubMed]

27. Nakamura, K.; Yoshikawa, N.; Yamaguchi, Y.; Kagota, S.; Shinozuka, K.; Kunitomo, M. Antitumor effect of cordycepin ( $3^{\prime}$-deoxyadenosine) on mouse melanoma and lung carcinoma cells involves adenosine A3 receptor stimulation. Anticancer Res. 2006, 26, 43-47.

28. Saitoh, M.; Nagai, K.; Nakagawa, K.; Yamamura, T.; Yamamoto, S.; Nishizaki, T. Adenosine induces apoptosis in the human gastric cancer cells via an intrinsic pathway relevant to activation of AMP-activated protein kinase. Biochem. Pharmacol. 2004, 67, 2005-2011. [CrossRef]

29. Gessi, S.; Merighi, S.; Sacchetto, V.; Simioni, C.; Borea, P.A. Adenosine receptors and cancer. Biochim. Biophys. Acta 2011, 1808, 1400-1412. [CrossRef]

30. Cavuoto, P.; Fenech, M.F. A review of methionine dependency and the role of methionine restriction in cancer growth control and life-span extension. Cancer Treat. Rev. 2012, 38, 726-736. [CrossRef]

31. Maddocks, O.D.K.; Athineos, D.; Cheung, E.C.; Lee, P.; Zhang, T.; Van Den Broek, N.J.F.; Mackay, G.M.; Labuschagne, C.F.; Gay, D.; Kruiswijk, F.; et al. Modulating the therapeutic response of tumours to dietary serine and glycine starvation. Nature 2017, 544, 372-376. [CrossRef]

32. Yeh, C.L.; Pai, M.H.; Li, C.C.; Tsai, Y.L.; Yeh, S.L. Effect of arginine on angiogenesis induced by human colon cancer: In vitro and in vivo studies. J. Nutr Biochem 2010, 21, 538-543. [CrossRef] [PubMed]

33. De Mejia, E.G.; Dia, V.P. The role of nutraceutical proteins and peptides in apoptosis, angiogenesis, and metastasis of cancer cells. Cancer Metastasis Rev. 2010, 29, 511-528. [CrossRef] [PubMed]

(C) 2018 by the authors. Licensee MDPI, Basel, Switzerland. This article is an open access article distributed under the terms and conditions of the Creative Commons Attribution (CC BY) license (http:// creativecommons.org/licenses/by/4.0/). 